\title{
Analysing the Required Properties of Business Simulation Games to Be Used in E-Learning and Education
}

\author{
Andrej Jerman Blažičč ${ }^{1}$ Claudia Ribeiro ${ }^{2}$, João Fernandes ${ }^{2}$, João Pereira ${ }^{2}$, Tanja Arh ${ }^{1}$ \\ ${ }^{1}$ Laboratory for Open Systems and Networks, Jožef Stefan Institute, Ljubljana, Slovenia \\ ${ }^{2}$ INESC-ID, Department of Information Systems and Computer Science, \\ Instituto Superior Técnico, Lisbon, Portugal \\ Email: andrejcek@e5.ijs.si, claudia.sofia.ribeiro@ist.utl.pt, joao.costa.fernandes@ist.utl.pt, \\ joao.madeiras.pereira@ist.utl.pt,tanja@e5.ijs.si
}

Received August 28, 2012; revised September 10, 2012; accepted September 19, 2012

\begin{abstract}
Business simulation games are considered as effective tools for the empowerment and mediation of business content learning. They act as serious games which contribute to learning through a simulation of real-life situations and business environments. They are especially useful in the area of business management processes and business strategies. The blending of designed simulation technology and content curricula offers participants (players, students) a risk-free opportunity to test out a range of relevant strategies to drive business results. By customizing computer-based business simulations, participants can integrate key strategic and financial priorities. This paper provides a brief review of business simulations that serve learning purposes. The first part presents a short introduction and description of business games and their evaluation properties, and the second part provides a brief evaluation and analysis of selected business simulation games.
\end{abstract}

Keywords: Serious Games; Business Simulation Games; E-Learning; Problem-Based Learning; Business Environment

\section{Introduction}

Serious computer games are part of the new emerging education environment that is based on sophisticated technology with elements of entertainment. Michael and Chen [1] give the following definition: "A serious game is a game in which education (in its various forms) is the primary goal, rather than entertainment". It is worth nothing that Huizinga [2] defined games as a free activity standing quite consciously outside "ordinary life", and as being "not serious"-following this definition games cannot be serious. Callois [3] similarly defined games as voluntary, therefore also conflicting with the notion of serious games. This gives a good indication of the kinds of contradictions found in comparisons of the available literature. Serious (computer) games have been demonstrated to provoke active learner involvement through exploration, experimentation, competition and co-operation. They have been seen as a good opportunity for supporting learning processes because of their capability to increase visualizations and challenge student creativity [4]. Academia has been studying video games and their use in the learning environment in the last two decades. However the area is still treated as a novel approach in learning in both educational systems: within the universi- ties and within the lifelong learning programs [5]. The search for a new position of educational games within university programs is still an issue under discussion, as the introduction of gaming slowly moving the setting of education towards interactive content, worthy of exploration. The "fruits" of game-based learning research that resulted in applicable results are now starting to penetrate the classroom. Serious computer games have shown that they can gather useful learning content based on known educational material [6].

There are specific educational domains where gamebased learning concepts and approaches have shown a high learning value. The main property of game-based learning is the capability to motivate and teach in ways that other methods cannot, a unique solution in the vast area of training issues studied by trainers and researchers [7]. In traditional learning, students often meet with studying literature in form of PDFs, PowerPoint presentations or any other kind of digital media sources. Using the knowledge that has been provided in classrooms and at lectures, real situations can be practiced and simulated mainly by training within the gaming environment. The games and simulated real environments allow learners/students to use their newly acquired skills and knowledge by applying them to a competitive challenge offered 
within these multimedia tools. Nowadays students look upon technology and the digital environment as an integral part of life, and games are considered to be a tool that they take for granted. This contributes to the better use of simulations and experiential learning technologies that have a broad range of applications in the studying environment [8].

Serious games have the potential to significantly improve training and education activities and initiatives. As a part of serious computer games, business simulation games support training and learning that is focused on management of economic processes. Business simulation games bring the effective methods of learning and experience through business challenges that students usually need to meet before setting foot in the real world. They help students to grasp key business and management concepts and make effective business decisions by using a combination of visual, auditory and hands-on approaches. Business simulation games can be usually presented as a training technique in which participants consider sequences of problems and take decisions. It is a simulation which consists of sequential decision-making exercises structured around a hypothetical model of the operations of an organization. Because they simulate the real-world system, they can often be used as a teaching method at university level, particularly in business schools, but also for executive education [9].

By browsing the vast number of business simulation games in the computer technology environment, it has become difficult to find a game that would be able to support all possible aspects of business and all learning outcomes. In general they can be either too time consuming, too complex for classrooms or too engaging so that any intended educational focus (by educators) appears to be hard to construct [10].

Business simulation games can be allocated to different categories, based on the variety of "learning" content that can be digested in order to produce learning outcomes, as the place of serious computer games in business education depends on the purpose of their usage and achieved goals. Unfortunately, by playing the few games that were picked out from the current stage of "the world of serious business games" is not fully sufficient to present the whole knowledge area existing in business education. However, this paper shows that, different games can provide different skills and training focuses. By deciding/selecting the fields of business education where the support of individual games is necessary, the most appropriate game for the required training can be found, as the selection of business games is sufficiently large and rich. By reviewing several games that are presented in this paper, it was found that different limitations exist which may or may not support the envisaged educational aims, the educator's objectives and planned outcomes.
Some games are designed at a very high level intended to fulfill the learning methods, while some games are very poor and do not meet expectations regarding the learning purposes.

This paper provides a brief review of the usage of serious simulation games. It presents several types of games that are available and explains their properties in order to help bring educators/learners closer to the possibility of using games to support their educational aims, objectives and planned outcomes.

\section{Related Work}

Various authors anticipate the great opportunities of games (and simulations) in education, because of their positive effects on learning outcomes e.g. [11-13]. Games have been demonstrated to provoke active learner involvement through exploration, experimentation, competition and co-operation. They support learning because of increased visualization and challenged creativity. They also address the changing competences needed in the information age: self-regulation, information skills, networked cooperation, problem-solving strategies, critical thinking and creativity. Hence, games are an effective tool for mediating learning. Computer games not only convey hard skills such as the understanding of how complex systems operate, production networks being one of them, but also mediate soft skills such as collaboration and communication [14]. Though Salen et al. [15] have produced a well-elaborated conceptual framework for the analysis of games, they pay little attention to education and learning. De Freitas et al. [16] review various frameworks that can help teachers evaluate the appropriateness of educational games and simulations for a particular e-learning context. Their paper presents a 4-dimensional framework that extends the existing ones. The framework focuses on evaluation rather than design and thus it does not present strategies or methods for game design. In order to strengthen the link between game design and educational design, Burgos et al. [17] have suggested developing a framework based on the IMS-Learning Design technology specification. The practical application of the framework is hampered, because it would require complex tooling. Armory [11] presents a game object model for the development and analysis of computer video games. The model identifies the key concepts of games and it has recently been updated to include educational goals. Due to its general and theoretical level of reasoning, it is of little direct significance to practical, educational game design [18]. Because of the insurmountable diversity of games, Björk et al. [19] have suggested to work with game design patterns, which describe well-identified recurring problems in game design and offer reusable solutions. The approach neatly addresses the diversity of 
the domain: It provides a shared vocabulary of game elements, allows structured comparison between games, and supports component-based tooling. Over 200 game design patterns have been identified. However, the frame-work provides only very little support for the integration of patterns into an appropriate game. Dickey's [20] research suggests that various game design strategies for achieving player engagement (like narrative, viewpoint, setting and roles) can be applied for the design of engaging learning environments. Kiili [18] focuses on games for experiential learning and looks into the conditions that contribute to achieving an experiential flow. Although the research of Kiili [18] explicitly links educational theory with game design, it sincerely reports on its inability to address or improve game design. Various approaches have been developed to cover specific types of games, for instance classroom games or massive multi-user online games [21]. These approaches have only little significance for serious game design. For audio-visual design and narrative, various frameworks are available, but these are not necessarily tuned to audio-visuals in serious games design [22,23]. Altogether, though quite a number of valuable frameworks is available to enhance our understanding of games, these generally provide only little design directions, often lack a pedagogical perspective, and fail to suggest how to deal with game complexity.

\section{Definitions and Selection of the Required Game Parameters and Games}

Presently, business simulation games are running on personal computers and more recently on the internet as web-based applications. They allow quick and easy input, easily changeable business environments, and graphical display of results. For the purpose of this paper, the evaluation is going to be based only on computerized business games. Computerized business games, i.e. business simulation games, can be classified according to several properties. The first taxonomies and classifications of business simulations were already introduced and presented by Greenlaw et al. [24]. However, according to Biggs [25], this particular identical taxonomy was used while he attempted to classify the computerized business management simulations. While establishing the background and the nature of the business management simulation, Biggs [25] states there is no single way to define the classification of business games. Business games can be classified on a number of dimensions. The next attempt to classify business games used in distance education courses was presented by Pillutla [26]. Unfortunately, his classification of business games was merely according to "how they are distributed", which leads to our conclusion that the "web-based" business games do not gather the whole spectrum of business simulation games. For instance, a "non-web-based" business game can be played on a personal computer independently without any support of information communication technology. For the survey of "web-based" and "non-webbased" business games, Biggs' classification is going to be used in this paper.

For the purpose of this paper, the evaluation properties have been classified into the two major groups. The first group - the technical classification - presents the properties using the technical data that describe the business simulation game and the second group - the usability classification - presents the variety of dimensions that describes types of usability characteristics. All properties are described in the following sections and have been used in the Table 1.

\subsection{Technical Properties}

First, the business games can be classified by subject matter as being available on a web-based platform or a desktop-based platform. Web-based games can be played within the modern web browser. The desktop games need to be pre-installed in order to play them. The second matter that is important is their availability: Some games are free of use, meaning no purchase is required where users usually need to sign-in in order to make the personal profile account (free of charge) on line, to be used every time they play. On the contrary, to play some games, users need to buy the original $C D / D V D$ or purchase the licensed code that is required when downloading the game via downloaded application/client and later installed on the personal computer. Third, business games can be played in single or multiplayer mode. Many games can be played individually, but in some games the complexity is frequently such that team play is highly recommended. In addition it is sometimes recommended, to play in multiplayer mode, as a team, for behavioural reasons since the participants learn to work in groups, deal with conflicts, communicate, motivate others, and exercise leadership. Some games are also set to play in the multiplayer mode in order for participants to play against each other, for example to be competitive and successful in business. On the other hand, some games are recommended for individual play because it is seen as relatively simple or so that individual performance can be assessed. The fourth dimension of the game classifies games according to whether they are played in $2 D$ or $3 D$ environment. 2D games usually don't require a high graphical performance and can be run on computers with minimum technical specification, while 3D games can be run on high graphic scale characteristics using maximum computer requirements. The fifth dimension is the number of users that are involved. Some on-line business 
games have a vast number of registered users which can demonstrate whether a game is popular and motivational to play or not. The sixth and last dimension is the year of publishing. Many business games that have been development are usually out of date, or cannot be run on the modern operation systems.

\subsection{Usability Properties}

In the second group of classification, business games may be classified on a number of dimensions that identify the e-learning and usability metrics in order to serve purposes of selecting a business game. First, business games can be functional or total enterprise. A functional business game is one which is designed to focus specifically on problems of decision-making as seen in one particular area. In contrast, a total enterprise game is one "designed to give people experience in making decisions at a top executive level and in which decision from one functional area interact with those made in other areas of the company" [25]. Total enterprise games would be used in courses or training programs which the objective is to give an overview of business management. Games can be competitive or non-competitive. While playing a game, it is important to consider whether the decisions of the players/users influence the results of one another (competitive) or not (not-competitive). For example, in the competitive type, if all users have the same starting point (amount of money), and company 1 charges a lower price than company 2 , company 1 will sell more than company 2. In a non-competitive game, on the other hand, the participants compete against the computer model or an environment rather than one another. A business game can be interactive or non-interactive. When players/users play an interactive game, it means they interact with the computer, i.e. that participants respond to questions at the computer, receive immediate responses and then submit additional decisions. In non-interactive games, decisions are submitted to the game administrator, run through the program, and the results are returned later. Regarding the game background environment, a business game can be industry-specific or generic, depending upon whether or not a specific industry is being simulated. In an industry-specific game, the authors attempt to replicate a real industry environment. In the generic type, games attempt to simulate only general business relationships where players/users can deal with any kind of general business processes and markets. Business games can be classified as deterministic or stochastic types of games, depending on the extent to which random events occur. The stochastic alternative is probabilistic, including the factor of chance of elements. A briefing system shows at what level a business game is provided with information and data that guides players through the game. Business games can have a high level of briefing system and guide the player throughout the game, or a low level of briefing system, where the player must study the game in order to play it. The seventh dimension is the required background knowledge. Some business games don't require business or management background knowledge, which means they can be played by any player interested in business and economy, whereas some games require basic or advanced business management knowledge in order to play them. Those games are usually designed to train and teach specific business or management processes. Business games may be classified according to the time period simulated. Does each decision set cover one day, one week, one quarter of a year, a year, etc.? The time period simulated is important since it indicates whether participants are to focus on short term operating decisions, longer term strategic decisions, or both. Following this background information and dimensions along which business games may be evaluated, we will proceed to select business simulation games. It is important to consider what kind of learning outcomes the games meet. Different games have different outcomes. Some of the most recognizes outcomes are: Strategic management, decision making skills, project business management, etc. [25].

With the usability properties identified, we can start with a selection of business games and decide whether a business game would help to meet the learning purpose. In business simulation games, players assume the role of decision-makers in organizations. The fact that players make decisions for a number of decision periods forces them to live with the consequences of their previous decisions.

\section{The Selection of Business Games}

When selecting business games for evaluation, an internet search was conducted, and we were confronted with the countless computerized games that are described as a business games. The Wide World Web provided us with enormous and countless lists of business games. For example, in Wikipedia, a list of business games contains hundreds of games that are listed in alphabetical and chronological order. However, most of the games listed are considered to be more entertainment than edutainment, which takes us out of our focus of selection (so called "tycoon" games that cover different business areas-Zoo Tycoon, Rollercoaster, Hotel Tycoon, can be potentially used as a learning tool or for education purposes, but they are more unlikely to be classified as serious games, because they manly originate from the entertainment industry, and are classified as commercial games). However, at Business Simulation Games_-BSG

(www.businesssimulationgames.com), we can find useful criteria that were used as a baseline in selecting the busi- 
ness simulation games. In order to be classified as a business game, a game has to be: Realistic, engaging, motivating, popular and user-friendly.

With these criteria, a selection of games was made, where the focus was merely on how popular a game is (how many users a selected game has), how realistic the game is (if a game covers a situation or topic that can be mirrored in the real world) and how motivating a game is(in order to keep the player motivated with an attractive graphical environment and a winning prize if the goal is successfully reached). The game has to be user-friendly, which excludes games that require additional tutorials and instructions on how to play them.

Another round of selection was made using the source from business-game-related article reviews. In State of The Art of Serious Games for Business and Industry, Riedel [27] has listed the selection of 39 serious games that covered topic such as finance, management, product management, industry management, leadership, etc. The list of games has been conducted in 1998 as part of the COSIGA project. Games that have been developed by GALA project (http://www.elios.dibe.unige.it/gala/) have been added to the list additionally. By gathering all selected sources, the following games were selected.

\subsection{INNOV8}

The INNOV8, also known as the IBM Business Process Management (BPM) simulation game is a role-playing game that simulates business process management in a 3D environment. The IBM SOA (Self-oriented architecture) team originally created the game to help educate potential SOA clients. The initial version was only open to the academic community and has been in use at over a 1000 universities and colleges (as far and wide as Beijing and Manchester) since its launch in 2007. The game gives the user a chance to experience and learn about BPM and understand how information and decisions are processed in the business world. The following picture (Figure 1) shows the player's interaction with virtual avatars.

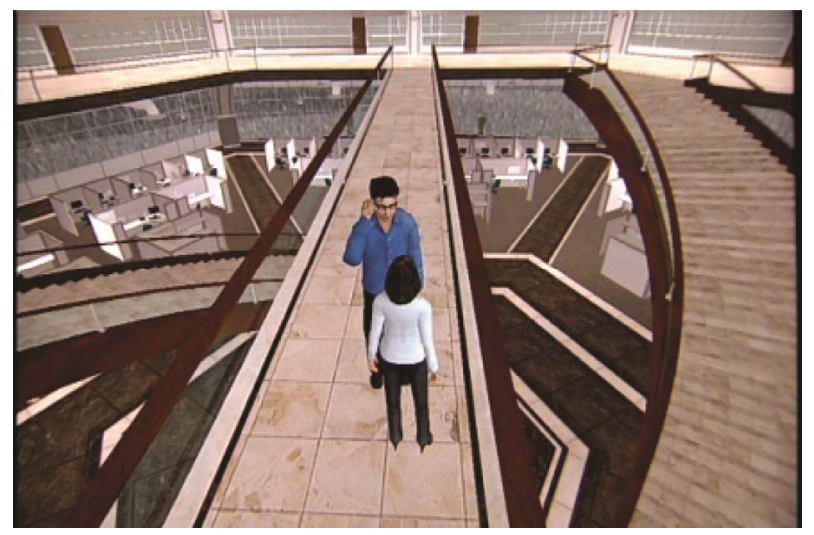

Figure 1. A screenshot of the 3D environment of INNOV8.

\subsection{Virtonomics}

Virtonomics is a business-strategy oriented on-line game played as an MMOG (massive multiplayer online game) where the basics of management are tested. It is designed for fans of economic and strategic games, and to study the basics of management. The game itself requires an understanding of laws of real life economy, business and finance, yet players do not need a deeper understanding of economics or any special background education to take part. The game is helpful in meeting interesting people with common interests and making useful connections.

\section{3. eRepublik}

eRepublik (www.erepublik.com) is a massive multiplayer online strategic game developed by Republik labs. It is free of use and combines social networking elements (Facebook, LinkedIn, etc.). The game is set in a mirror world called the New World. The players take a role of citizens where they can participate in daily activities. The game play is based on a war-time situation which takes a potentially crucial role by increasing the economic or political power of a country. A nation that has experienced and battle-hardened citizens can become a global power and grow global economy business.

\subsection{Virtual Leader}

Virtual Leader is a simulation training game which is focused to develop leadership skills and aspects through various scenarios in a "virtual world". It is a role-playing 3D game with "sim-like" graphical environment. Virtual Leader provides a nice and friendly e-learning platform in a form of "role-play-game" that allows users to develop necessary skills, that are relevant and needed in business environment. The following picture (Figure 2) presents the virtual meeting session in progress, where player interact with virtual characters.

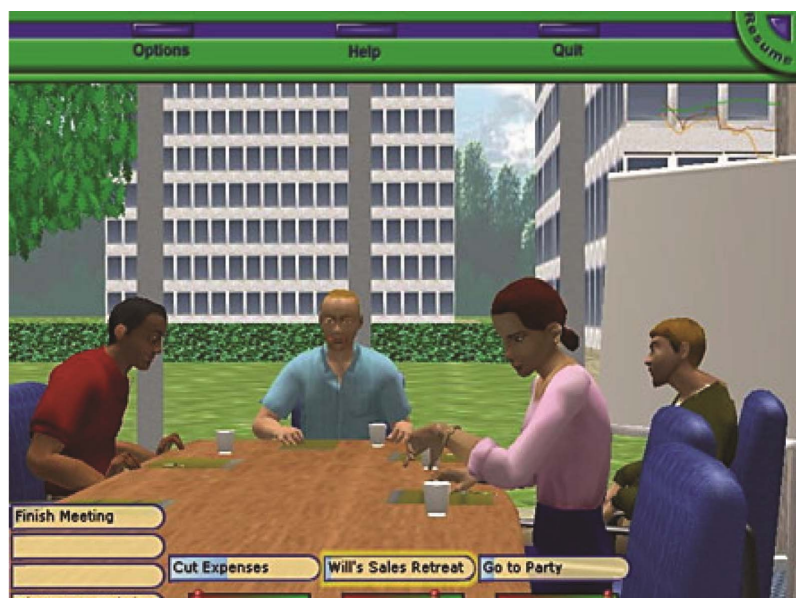

Figure 2. A screenshot of business meeting at Virtual Leader simulation. 


\subsection{Business Tycoon Online}

Business Tycoon Online (bto.dovogame.com) is innovative well known massively multiplayer online game that originated in Asia. The game supports thousands of players simultaneously. It is designed as a business simulator where players must rise to the top of the social ladder as industrial tycoons. Players take the role of entrepreneur in a virtual business world where they starts their own business to break through constant challenges to eventually end with building up a universal corporation or a powerful business empire.

\subsection{Wall Street Survival}

Wall Street Survivor (www.wallstreetsurvivor.com) is a web-based financial (stock market) game with real market data, real stock symbols, and real market tracking, all accounted for on an impressively simulated trading platform. It simulates real-time bid/ask trade fills, as well as streaming profit and loss pages. In order to play the game, a profile account needs to be created and registered. Once a user is registered at Wall Street Survivor, he/she receives an account with $\$ 100000.00$ in simulated money to trade with.

\subsection{The Beer Game}

The Beer distribution game, also known as The Beer Game is a role-play supply-chain simulation game that lets students experience typical coordination problems of supply chains without information sharing and collaboration. The purpose of the game is to understand the distribution side dynamics of the multi-echelon supply chain used to distribute a single item, in this case cases of beer. The aim is to meet customer demand for barrels of beer through the distribution side of a multi-stage supply chain with minimal expenditure on back orders and inventory.

\subsection{Big Oil: Build an Oil Empire}

Big Oil: Build an Oil Empire is a business strategy game where users take a role of an oil baron set in times of the oil industry pioneers. They aim to build their own oil empire by taking control of the entire oil business process, from surveying, drilling, and extracting to refining, selling, and market investments. Big Oil lets users build an oil empire by drilling for oil, shipping it to refineries around the world, and eventually processing it into products that can be sold to the public. To play the game user/player can choose from more than 15 scenarios based on historical events such as the Oil Crisis, Lenin's death, Apartheid, etc.

\section{Analysis and Assessment of Selected Business Games}

Below we present the evaluation parameters and results for the selected games.

Table 1. Evaluation parameters and results.

\begin{tabular}{|c|c|c|c|c|c|c|c|c|}
\hline & eRepublik & Virtonomics & $\begin{array}{c}\text { Business } \\
\text { tycoon online }\end{array}$ & IBM INNOV8 & Virtual leader & $\begin{array}{l}\text { Big oil: Build } \\
\text { an oil empire }\end{array}$ & $\begin{array}{l}\text { Wall street } \\
\text { survivor }\end{array}$ & The beer game \\
\hline $\begin{array}{l}\text { Web-based/ } \\
\text { desktop }\end{array}$ & Web-based & Web-based & Web-based & Desktop & Desktop & Desktop & Web-based & Web-based \\
\hline Distribution & Republik labs & $\begin{array}{l}\text { Virtonomics } \\
\text { team }\end{array}$ & Dovogame & IBM & SimuLearn & Try sinergy & $\begin{array}{l}\text { Wall Street } \\
\text { Survivor }\end{array}$ & MTI sloan \\
\hline $\begin{array}{c}\text { Year of } \\
\text { publishing }\end{array}$ & 2008 & 2009 & 2010 & 2007 & 2003 & 2006 & $\mathrm{n} / \mathrm{a}$ & $\mathrm{n} / \mathrm{a}$ \\
\hline dimensions & $2 \mathrm{D}$ & $2 \mathrm{D}$ & $2 \mathrm{D}$ & $3 \mathrm{D}$ & $2 \mathrm{D}$ & $3 \mathrm{D}$ & $2 \mathrm{D}$ & $2 \mathrm{D}$ \\
\hline Platform & Any & Any & Any & PC Windows & PC Windows & PC Windows & Any & Any \\
\hline Free of use & Yes & Yes & Yes & $\begin{array}{l}\text { Yes with } \\
\text { approved } \\
\text { registration }\end{array}$ & $\begin{array}{l}\text { Purchase } \\
\text { required }\end{array}$ & $\begin{array}{l}\text { Purchase } \\
\text { required }\end{array}$ & Yes & Yes \\
\hline Time period & Min. 1 month & Min. 1.5 month & Min. 1 month & 2 to 4 hours & 6 to 9 hours & $8-10$ hours & Min. 1 month & 1 to 1.5 hours \\
\hline $\begin{array}{l}\text { Industry } \\
\text { specific or } \\
\text { generic }\end{array}$ & Generic & Generic & Industrial & Industrial & Industrial & Industrial & Generic & Industrial \\
\hline $\begin{array}{c}\text { Degree of } \\
\text { complexity }\end{array}$ & Low & Medium & Medium & Low & Medium & Low & Low & Low \\
\hline $\begin{array}{c}\text { Functional or } \\
\text { enterprise }\end{array}$ & Enterprise & Total enterprise & Total enterprise & Enterprise & Enterprise & Functional & Functional & Functional \\
\hline
\end{tabular}


Continued

\begin{tabular}{|c|c|c|c|c|c|c|c|c|}
\hline $\begin{array}{c}\text { Competitive or } \\
\text { non-competitive }\end{array}$ & Competitive & Competitive & Competitive & Non-competitive & eNon-competitive & Competitive & Competitive & Competitive \\
\hline Feedback system & $\begin{array}{l}\text { Experience } \\
\text { points }\end{array}$ & $\begin{array}{c}\text { Experience } \\
\text { points, virtual } \\
\text { money income }\end{array}$ & $\begin{array}{l}\text { Points received } \\
\text { in order for } \\
\text { level upgrading }\end{array}$ & Points received & Statistic charts & $\begin{array}{c}\text { Experience } \\
\text { points, virtual } \\
\text { money }\end{array}$ & Virtual money & Statistic charts \\
\hline $\begin{array}{l}\text { Deterministic or } \\
\text { stochastic }\end{array}$ & Deterministic & Deterministic & Stochastic & Deterministic & Deterministic & Deterministic & Stochastic & Deterministic \\
\hline Briefing systems & $\begin{array}{l}\text { Tutorial video, } \\
\text { guidance of } \\
\text { personal mentor }\end{array}$ & $\begin{array}{c}\text { Poorly } \\
\text { supported with } \\
\text { mail from } \\
\text { virtual } \\
\text { administrator }\end{array}$ & $\begin{array}{l}\text { Supported with } \\
\text { mails from } \\
\text { virtual } \\
\text { administrator }\end{array}$ & $\begin{array}{l}\text { The virtual note } \\
\text { support }\end{array}$ & $\begin{array}{c}\text { Text } \\
\text { s instructions and } \\
\text { audio/video } \\
\text { tutorial }\end{array}$ & $\begin{array}{c}\text { Virtual } \\
\text { assistant } \\
\text { provided }\end{array}$ & Text tutorial & Text tutorial \\
\hline $\begin{array}{l}\text { Learning } \\
\text { objectives }\end{array}$ & $\begin{array}{l}\text { Strategy skills, } \\
\text { politic- } \\
\text { management } \\
\text { skills }\end{array}$ & $\begin{array}{c}\text { Strategy skills, } \\
\text { strategic } \\
\text { management, } \\
\text { business } \\
\text { decision } \\
\text { making }\end{array}$ & $\begin{array}{c}\text { Strategic skills, } \\
\text { business } \\
\text { decision } \\
\text { making skills }\end{array}$ & $\begin{array}{c}\text { Business } \\
\text { project } \\
\text { management }\end{array}$ & Leadership skills & $\begin{array}{l}\text { Business } \\
\text { strategy }\end{array}$ & $\begin{array}{c}\text { Financial skills, } \\
\text { stockbroker } \\
\text { skills }\end{array}$ & $\begin{array}{l}\text { Coordination } \\
\text { and logistic } \\
\text { skills }\end{array}$ \\
\hline $\begin{array}{l}\text { Background } \\
\text { knowledge }\end{array}$ & Not required & Required & Not required & Required & Not required & Not required & Required & Not required \\
\hline Interactivity type & Yes & Yes & Yes & No & No & No & No & No \\
\hline
\end{tabular}

${ }^{* *}$ The information has been last updated in 2010 .

\section{Analysis of the Results}

With the evaluation of selected games complete, some games present a very high level of design intended to fulfil the learning methods while others show their poor graphical interface and do not meet the requirements that are expected in order to foreground the learning purpose. Overall, business simulation games can be allocated to different types or categories, based on the variety of "learning" content that can be "digested" in order to extract the learning outcome as the place of business simulation games in business education depends on the purpose of their usage and achieved goals. While selecting the most adequate business simulation game, it is important to know that the game scenario must meet the educators or learners expectations. At this point it is important to note that such games must have highly developed segments or levels of reality. The better the imitation of reality in a game is, the more phenomena and the higher level of relations complexity between them are encompassed by the game scenario. Such games enable faster transfer of the experiences of participants directly to their learning target. In our case, IBM's INNOV8 was demonstrated as a good example. INNOV8 is a game with highquality graphics, cut scenes, scenarios and an interesting walkthrough. According to the study carried out by Ewing Kauffman Foundation (2008), the game proves to be an effective way of engaging students by teaching them leadership, project management, innovation and entrepreneurship skills. From a user point of view it can be expected that with the game scenarios engaged, users are far more likely to retain what they have learned than those taught by use of traditional lectures and case-study methods. It gives a good opportunity to explore how to learn about business process management and to collaborate with virtual characters to map out business processes, identify process bottlenecks and explore what- if scenarios. It is also provided with clear and easy-to-learn player's interface, meaning it is very easy to control the game.

On the other hand, the Beer game gives the impression of a very poor level of user satisfaction. While, the game itself brings a good example of realistic simulation of supply chain and the bullwhip effect which is a well- known phenomenon and a prominent symptom of coordination problems in supply chains, it has very poor graphics. The game consists of poor GUI (graphic users interface) and few graphical objects: Beer barrels, a transport truck, a factory image and beer storage. Functionally, there is nothing much to do. Game play is on the basic level: Inputting the number of beer units that the player needs to send to costumers. With no sufficiently presented scenario, players are more likely to be confronted with a hectic learning curve and subsequent extreme dullness.

From this aspect, a game that is considered with poor functionality is Virtual Leader. Game play focuses only on choosing the right set of dialogues with virtual characters. Yet, the game provides excellent background materials that bring players up to speed to their involvement and to quickly engage in to the game. In other 
hand, MMOG business games (Virotnomics, eRepublik, Business Tycoon On-Line), challenge players to get to know the whole functionality of their game-menu and GUIs tool bars without any "quick-to-learn" tutorial support. In general the selected games can be helpful if they demonstrate some aspects of strategy business, decision making processes business management and organization activities that helps in changing the player attitudes and improve better performance.

Overall, the players who will use selected games must be provided with a player's manual which represents the "rules of the game", describes the environment, and gives a starting point to the game. eRepublik gives a good example. A virtual mentor is included to guide players through the game and provide the explanation of the game basics. INNOV8 and Virtual Leader also do a good job supporting players with necessary explanations and useful information, while Virtonomics, Big Oil, Wall Street Survival and Beer Game have no special intent to provide a player manual, and give poor support in gameplay.

\section{Evaluation and Discussion}

Business simulation games make a good attempt to capture and combine virtual reality technologies and engaging components of video games in the simulations offered within serious games. Bringing the massive size, resources and technology of video games industry, modern business games are now bringing learners in to an environment where business (management) processes can have a major role. Unfortunately, to this good property many games involve only quantitative variables while ignoring human elements of organization. Wawer et al. [28] pointed out some limitations in the use of business simulation games:

- Considerable simplification of reality;

- Lack of player's responsibility for his/her decisions;

- Necessity of engagement of area and hardware resources;

- Limitation of education to the scope of the game;

- Games are treated as entertainment rather than as education;

- Behaviours and poses of game participants differ significantly from their behaviours and poses in real life.

In order for simulation games to meet the requirements for didactic tools and learning methods, they need to be extremely precise in imitating market realities. At this point, there is a need for game developers to focus on the monitoring/assessment of the adequacy of the available games regarding business market reality (business ecosystems) and to propose updating of the models imitating the current or predicted market situation. The use of an obsolete (outdated) model can lead to a permanently negative opinion of the game participant about this form of education. In our case, eRepublik is very limited regarding player expectations. Not many realistic actions occur in the game (wars are the only factor driving the economy, running companies is too easy, the source and amount of information is limited, etc.) therefore the game can easily decrease motivation. On the contrary, SimuLearns' Virtual Leader is a nice attempt at simulating human behaviour in order to practice the tenets of threeto-one leadership with imitations of business meeting sessions which can be mirrored into the real-life situations. Beside the attractive virtual reality, simulation games can keep learners motivated also with monetary rewards. For example, Wall Street Survivor is not just a mere stock simulator, it provides a competition by giving some attractive real money prizes to the top players in order to keep them motivated. In general, the games that were selected, demonstrated that it can be helpful if they represent the aspects of business strategy, decision-making processes, business management and organizational activities that helps to change player attitudes and improve performance. They provide user experience in the application of statistical and analytical methods that are used as economic tools.

\section{Conclusion}

Nowadays we live in an era where the internet is used as a powerful tool to facilitate managerial learning through business simulation applications. Business simulation games based on the use of computers and internet capabilities are a reality and they are expected to be the default tool in many areas in the future. Due to their limitations or functionalities many of them will be adapted or re-modelled [30]. A selection of business simulation games has been made and evaluation process has been done which has provided the expected results. Different limitations appear, that may or may not support the envisaged educational aims, the educator's objectives and planned outcomes. Some games have a very high level of complexity intended to fulfil the learning methods and some games are very poor and do not meet the requirements that are expected to foreground the learning purpose. Generally, it is not possible to implement all necessary learning conditions that cover all areas of knowledge. Yet, by defining types of learning outcomes that need to be fulfilled and what fields of business education need to be "trained", the combination of most appropriate games can be created in the sufficiently large and rich set of business games in order to meet the educator's planned outcomes [10]. All in all, business simulation games are one of the most important methods of acquiring technical and problem-related knowledge. At this point, business simulation games should be used as a didactic method whenever conditions meet the learning goals and outcomes. 


\section{Acknowledgements}

This work was supported by FCT (INESC-ID multiannual funding) through the PIDDAC Program funds. The authors also would like to acknowledge to the European funded Project UNITE (FP7 248583), namely its secondment programme coordinated by UNINOVA-GRIS, that supported the development of various ideas and concepts presented in this paper.

\section{REFERENCES}

[1] R. Michael David and S. L. Chen, "Serious Games in Defence Education: A Report into the Potential Educational Benefits of Education," Education Journal, Vol. 61, No. 3, 2005, pp. 1-95.

[2] J. Huizinga, "Nature and Significance of Play as a Cultural Phenomenon," The MIT Press, Cambridge/London, pp. 96-120.

[3] R. Caillois, "Man, Play, and Games," Schocken Books, New York, 1961. doi: $10.1177 / 101269027701200206$

[4] C. K. H. J. Riedel and J. B. Hauge, "State of the Art of Serious Games for Business and Industry," 17th International Conference on Concurrent Enterprising (ICE), Aachen, 20-22 June 2011, pp. 1-8.

[5] J. Aleckson, "Managing E-Learning," 2009. http://managingelearning.com/2009/01/19/definitions-seri ous-games-game-based-learning

[6] M. Pivec, "Editorial: Play and Learn: Potentials of GameBased Learning," British Journal of Educational Technology, Vol. 38, No. 3, 2007, pp. 387-393.

[7] M. Prensky, "Digital Game-Based Learning," Paragon House Publishers, Saint Paul, 2001.

[8] J. Herrington, R. Oliver and T. C. Reevers, "Patterns of Engagement in Authentic Online Learning Environments," Australian Journal of Educational Technology, Vol. 19, No. 1, 2007, pp. 59-71.

http://www.ascilite.org.au/ajet/ajet19/herrington.html

[9] M. G. Farkas, "Social Software in Libraries: Building Collaboration, Communication, and Community Online," Information Today, New Yersey, 2007.

[10] K. Royle, "Computer Games and Realising Their Learning Potential," 2011. http://www.gamebasedlearning.org.uk/content/view/67/60/ $1 / 1$

[11] A. Armory, "Game Object Model Version II: A Theoretical Framework for Educational Game Development," Educational Technology, Research and Development, Vol. 55, No. 1, 2008, pp. 51-77. doi: $10.1145 / 1655925.1656110$

[12] M. Prensky, "Learning in the Digital Age," Educational Leadership, Vol. 63, No. 4, 2006, pp. 8-13.

[13] C. N. Quinn, "Enganging Learning: Designing E-Learning Simulation Games," John Wiley and Sons Inc., San Francisco, 2005.

[14] B. Scholz-Reiter, S. Gavirey, W. Echelmeyer, T. Hamann and R. Doberenz, "Developing a Virtual Tutorial System for Online Simulation Games," Proceedings of the 30th SEFI Annual Conference, Firenze, 8-11 September 2002.

[15] K. Salen and E. Zimmerman, "Rules of Play: Game Design Fundamentals," MIT Press, Cambridge, 2004.

[16] S. De Freitas and M. Oliver, "How Can Exploratory Learning with Games and Simulations within the Curriculum Be Most Effectively Evaluated?" Computers and Education, Vol. 46, No. 3, 2006, pp. 249-264. doi:10.1016/j.compedu.2005.11.007

[17] D. Burgos, C. Tattersall and R. Koper, "Re-Purposing Existing Generic Games for E-Learning," Computers in $\mathrm{Hu}$ man Behaviour, Vol. 23, No. 6, 2007, pp. 2656-2667. doi:10.1016/j.chb.2006.08.002

[18] K. Killi, "Foundation for Problem-Based Gaming," British Journal of Educational Technology, Vol. 38, No. 3, 2007, pp. 394-404. doi:10.1111/j.1467-8535.2007.00704.x

[19] S. Björk and J. Holopainen, "Patterns in Game Design," Charles River Media, Hingham, 2005. doi:10.1073/pnas.0935845100

[20] M. D. Dickey, "Engaging by Design: How Engagement Strategies in Popular Computer and Video Games Can Inform Instructional Design," Educational Technology, Research and Development, Vol. 53. No. 2, 2005, pp. 6783. doi:10.1007/BF02504866

[21] C. A. Steinkühler, "Learning in Massively Multiplayer Online Games," Proceedings of the 6th International Conference on Learning Sciences, Santa Monica, 22-26 June 2004, pp. 521-528.

[22] J. Koumi, "Designing Video and Multimedia for Open and Flexibl eLearning," Routledge, New York, 2006.

[23] W. Westera, "A Didactic Framework for Audio Visual Design," Journal of Educational Media, Vol. 24, No. 2, 1999, pp. 87-102. doi:10.1080/1358165990240202

[24] P. S. Greenlaw, L. W. Herron and R. H. Rawdon, "Business Simulation in Industrial and University Education," Prentice Hall, Englewood Cliffs, 1962.

[25] W. D. Biggs, "Introduction to Computerized Business Management Simulations," In: J. Gentry, Ed., Guide to Business Gaming and Experiential Learning, Nichols/GP Publishing, East Brunswick, 1990, pp. 23-25.

[26] S. Pillutla, "Creating a Web-Based Simulation Gaming Exercise Using PEARL and Java Script," Simulation \& gaming, Vol. 34, No. 1, 2003, pp. 112-130. doi:10.1177/1046878102250635

[27] M. Wawer, M. Marek, P. Muryjas and R. Magdalena, "Business Simulation Games in Forming Students' Entrepreneurship," International Journal of Euro-Mediterranean Studies, Vol. 3, No. 1, 2010, pp. 49-73.

[28] D. Clark, "Games and E-Learning," Reproduction, Vol. 44, No. 3, 2006, pp. 1-46. http://www.caspianlearning.co.uk/Whtp_caspian_games_ 1.1.pdf

[29] B. Keys and J. Wolfe, "The Role of Management Games and Simulations in Education and Research," Journal of Management, Vol. 16, No. 2, 1990, pp. 307-336. doi: $10.1177 / 014920639001600205$. 